\title{
Нарцисс и «лишний человек»
}

\author{
Случай Герцена
}

\author{
ДЬЁРДЬ ЗОЛЬТАН ЙОЖА \\ JózSA György Zoltán, H-1114 Budapest, Hamzsabégi u. 33. \\ E-mail: jozsagyz@gmail.com
}

(Received: 21 March 2018; accepted: 27 May 2018)

\begin{abstract}
Reconsidering Beltov's figure in Herzen's Who is to Blame? will lead to revealing psychological traits relevant for the 'superfluous man'. Features of narcissism and a set of motifs related to the mythologeme of Narcissus traced in the text allow us to conclude that selfreflexion, autobiographical method in poetics as well as a dialogue between individualism and collectivism will prevail, surpassing social aspects.
\end{abstract}

Keywords: superfluous man, narcissism, Herzen, Ovid, mirror

Комплексный термин «лишний человек», продукт эпохи, породивший впоследствии перевоплощения литературного типа, как и всякий штамп, вызывает скепсис. Абстрагирующийся тип, черты характера которого заданы первыми авторами, пересоздававшими его в своих произведениях (Грибоедов, Пушкин, Лермонтов, Гончаров и В. А. Соллогуб), ${ }_{1}^{1}$ в результате продолжительной выкристаллизации удостаивается ранга названия заглавного героя повести Тургенева «Дневник лишнего человека». Уникальный вклад Герцена при оформлении фигуры Бельтова, ${ }^{2}$ который как раз сам многократно признается в своей «лишности» ${ }^{3}$ - как и сам автор, жаловавшийся на свой статус «колодника, выброшенного из общества», и на лишенность деятельности в письме к Захарьиной (XXI, 28), ${ }^{4}$ - состоит в скрупулезности разбора характера и психологии «сына века» в контексте его антецедентов. Итак, теоретическому изложению Герценом развития этого типа предшествует его концептуализирование на языке художественной прозы. Как известно, вереница

${ }^{1}$ Исключая роль героев романов А. де Мюссе и Б. Констана в генезисе «лишнего человека», Г. Н. Гай реконструирует прототип в радищевском образе Крестьянкина из «Путешествия из Санкт-Петербурга в Москву» в силу его обреченности на бездействие, отхода от пошлой среды, скуки и социального конфликта (ГАй 1959: 72-73).

${ }^{2}$ Как ни удивительно, авторы специальной монографии роман Герцена вовсе не упоминают (cp. ClaRDY-CLARDY 1980).

${ }^{3}$ В силу этого опровергается тезис Дж. Армтронг, указавшей на противоречия датировки возникновения термина. На ее взгляд, создание термина «лишний человек» принадлежит Тургеневу, и Герцен заимствовал его во время их частых собеседований в Париже (ARMSTRONG 1985: 279, 282).

${ }^{4}$ В предлагаемой статье все ссылки на произведения Герцена даются на основе издания ГЕРЦЕН 1954-1966 с указанием на том и на страницы. 
героев, либо возникших в диалоге с этими фигурами, либо причисляемых к данному типу по причине фальшивых интерпретаций, обладает в той или иной мере тождественными качествами, что приписывается в частности интертекстуальным диалогам между артефактами, не говоря о напластовании семантики, генерируемой рядом критических статей. Эти черты ощутимы в планах заимствований, психологии и общественных аспектов при построении литературных персонажей. В полемике 1960-х гг. в некотором смысле ставится под вопрос онтология типа: «Никакой особой эпохи „лишних людей““ в истории не было и не могло быть». Тем самым как бы разделены психологические и общественные аспекты, ассоциируемые с этим типом: «,,Ишний человек“ - трагическая фигура, и трагизм его, с одной стороны, - в разрыве с пошлой средой, а с другой, - в неспособности вступить в активную борьбу с ней» (Бурсов 1960: 107). Но эпитет «пошлый» предполагает ценностную вертикаль, прикованную к «лишнему человеку». При этом, исследователь как приверженец общественного детерминизма, считавший его «азбучной истиной еще для Белинского» (Бурсов 1960: 107), отклоняет негативный штамп, освобождая его от облигатных моральных и социально-направленных осуждений, и реабилитирует данный тип в выпаде против попытки Г. Макогоненко исключить Онегина из данной категории. За этим выводом стоит аргументация аксиологического разряда: «,,лишний человек“ - совсем не оскорбительная кличка, которая могла бы унизить Онегина» (Бурсов 1960: 109).

Несомненной продуктивности трактуемого нами литературного персонажа посвящен обзор, подробный и критический синтез, вышедший из-под пера Иванова-Разумника в 1911 г., где дистанцированно переосмыслены итоги полемик, утверждений, прозвучавших в критике и публицистике XIX в. Следующий шаг сделан в 1970 гг. американскими исследователями, расширившими в двух монографиях каталог таких героев в рамках русской классики и советской романистики (СHANCES 1978, CLARDY-CLARDy 1980). В трудах специалистов, однако, превалирует общественно-исторический подход. Апология Бурсова являет собой сдвиг, ибо, кроме повторения «замечательного тезиса Чернышевского», в ней «лишний человек» справедливо ставится на пьедестал «центрального героя русского романа». В факте канонизированности, с акцентом на беспрерывности литературной традиции, в этом «движении» «от Печорина - к Бельтову, от Бельтова - к Рудину», «прочно» вошедшем «в наши историко-литературные представления» таится перспективность литературного персонажа, значимость которого измеряется в категории «всечеловеческого содержания», атрибутируемого у Бурсова, увы, лишь фигуре Онегина (Бурсов 1960: 108, 110).

В высшей степени систематичный подход Герцена к изучению данного типа, отражая драматическую эволюцию его взглядов, последовательно акцентирует укорененность типа Онегина в русской культуре, его значимость и намерение отделить его от своих прототипов: «Онегин - это ни Гамлет, ни Фауст, ни Манфред, ни Оберман, ни Гренмар, ни Карл Моор; Онегин русский, он возможен лишь в России; там он необходим и там встречаешь 
его на каждом шагу» (VII, 204). Выводы сопоставительного анализа фигурирующих в списке персонажей однако показывают, что этих «философов» и «бунтарей» объединяет всего лишь «неприятие окружающего их мира, страдание и вынужденное одиночество» (ДРыжАковА 2004: 250). Между страшным приговором Герцена над «лишним человеком» и всепрощанием Достоевского резкий контраст: слова Достоевского, невольно затрагивающего симптоматику нарциссизма, гласят о страдальце-Онегине, не способном присвоить себе даже титул «эгоиста». Ибо появление его освещает ключевой миг, когда русский человек вдруг сознает себя европейцем, когда он улавливает взглядом в зеркале свой «европейский... элемент», чтобы подобно нарциссу уйти в «скептическое саморассматривание, саморазглядывание» (Достоевский 1979: 10-12). Суд Герцена, выдвигающий вечный конфликт индивида и коллектива, выносит обвинения доминантно общественно-политического разряда. При этом «лишность» типа у него реализуется в конфликте со средой: «Онегин - человек праздный потому, что он никогда и ничем не был занят; это лишний человек в той среде где он находится, не обладая никакой силой характера, чтобы вырваться из него» (VII, 204). В случае романа «Кто виноват?», касаясь проблемы интерпретации трагического финала Ю. Манн отклоняет воздействие мысли общественного детерминизма, указывая на элемент любовной коллизии, на которую «не влияет окружающая среда» (МАнн 1969: 262). Справедливости ради, мы заранее зафиксируем, что отношение Герцена к типу не так уж одностороннее. В его, порою противоречивых выводах об обобщенном типе целого «поколения» вместо обвинений против общественного строя скорее слышна мысль об опыте сверстников, свидетелей тех же самых исторических событий. ${ }^{5}$ Вслед за Горьким, который видит будушее Бельтова в альтернативах «войти в кружок петращевцев или встать в ряды эмигрантов» (Горький 1953: 251), в социологизирующем прочтении рок обрекает «лишнего человека» на скудный выбор между декабризмом и плоским бытом, ожидающим его на поприщах чиновника или помещика (Бурсов 1960: 108-109). В результате проигнорированы психологические и философские аспекты, пульсирующие уже в романе «Герой нашего времени». Фигурирующее еще в первой статье Белинского о «Евгении Онегине» выражение «самолюбивая посредственность», приписываемая «недюжинному человеку» (БЕлинский 7: 457), побуждает нас переосмыслить стремления Герцена к самовыражению и неотъемлемому от него самопознанию.

Герой прозы Герцена преимущественно автобиографический. В обоих сюжетах, идентифицированных Л. Гинзбург, присутствует элемент демонического (Гинзьург 1997: 13-15), герой якобы подвергается модификациям,

${ }^{5}$ При анализе генезиса «лишнего человека» 3. Гротхусен предлагает подход социокультуроглогического типа: исследователь возводит тип к поискам русского реализма, ориентированным на разъяснение теоретического вопроса о смене культурных и исторических парадигм: в ней первенствует роль поколений, силы, носителей совокупности культурных явлений, усвоенных в процессе воспитания и образования. Отсюда бунт носителей новых ценностей против традиции (ГРОТХУСЕН 2014: 97-98). 
постепенно преодолевая этапы романтического мечтателя, эгоиста, индивидуалиста, зато по определению А. Жука, начиная с очерка «Гофман» вплоть до романа «Кто виноват?» у Герцена в сущности «проходит один герой», созревание которого до знакомства Герцена с Лермонтовым происходит независимо от лермонтовского героя, а затем приобретает печоринские черты, ибо делимые протагонистами проблемы детерминированности и свободы определены дилеммой веры и безверия (Жук 1968: 65-66). Характерная для герценовского героя амбивалентность, связанная в ключе романтизма с постижением идеала, сосуществует с рядом философских оппозиций, синтез которых интригует самого автора как вопросы гносеологии и самопознания.

Абсолютизация Герценом индивида проявлена в разных дискурсах. Формулировка идеала, граничащая с пророчеством о грядущем культе индивида, налицо в повести «Первая встреча»: «Великий человек живет общею жизнью человечества, он не может быть холоден к судьбам мира...» (I, 117). Устремленность автобиографического героя к всеохватывающему универсализму можно восстановить на базе высказывания, попавшего в историософский контекст: идеал Герцена - ультимативный русский «ренессансный человек», Ломоносов, движимый в силу «своего энциклопедизма» «беспокойным желанием все понять» (VII, 188). ${ }^{6}$ Данная выдержка из брошюры «О развитии революционных идей в России», впрочем, ставится в самом начале предисловия к монографии Эльсберга с целью схватить сущность феномена самого Герцена (ЭльсьЕРг 1948: 3). Квинтэссенциальный момент философского подхода к величественной миссии личности, интегрируемый в образ литературного героя, получил достаточное освещение в науке: «личность для Герцена есть, прежде всего, - principium individuationis, некое первичное и неразложимое начало, творческий центр сил» (Гурвич-ЛишинеР 1996: 143). Идея личности, «свободной от всяческого догматизма», которая перенимается от сенсимонистов (Бродский 1945: 314-315), переплетается с императивом самоусовершенствования, диктуемым эмпирикой изолированности в ссылке, наставлениями бывшего масона А. Л. Витберга и мистическим ореолом любви к Захарьиной. Культ индивида, переходящий в романтическое жизнетворчество, с другой стороны, таит в себе риск его экстренных манифестаций (ЙожА 2018). Касательно антипода культа индивида, т. е. эгоизма, фальшиво понимаемого индивидуализма, гипертрофирующегося уже в признаки нарциссизма, размышления изложены, в том числе, в статье «По поводу одной драмы» (1842), и вписываются в парадигму вокруг романтического концепта о потерянном рае: «сломанное бытие» исходит из сосредоточенности на себе, «тесноты и неестественной для человека жизни праздности, преступного отчуждения от интересов всеобщих..., исключительного занятия собой, взаимного обоготворения» (II, 66). Индивидуализм и эгоизм представлены как безупречно дифференцированные в дневниковой записи 1842 года, содержащей думы по поводу произведения Ж. Санд «Орас», где замкнутый персонаж

\footnotetext{
${ }^{6}$ Все курсивы, кроме специально оговоренных - Д. З. Й.
} 
«не способен к сильной страсти, потому что не способен жить для другого, в другом» (здесь зашифрован тезис о неспособности эгоиста постичь гносеологический аспект бытия, понимаемой как нарциссический отказ от диалога). Превращение индивидуализма в эгоизм обусловлено «переходным временем борения двух миров» (как бы феномен переломных эпох), время дало «эгоизму несравненно блистательнейшую арену» (II, 222-223). Все эти мысли, возникновение которых хронологически совпадает с написанием романа «Кто виноват?», имеют свой вес в оформлении персонажа Бельтова. Романтизм здесь мыслится «как прикрытие для бездушного эгоизма» (СЕменов 1989: 92-93). Перелом, который пробужден статусом кризиса в личной судьбе Герцена и воспринимается им как некое «отрезвление», ознаменовывает этап в его «развитии», ибо «реализм, охватывающий все сферы жизни», равный «построению нового разумного мира» и окрашенный «гносеологическими» выводами, направлен на достижение «научной истины» (об этом см. ГинзБург 1997: 22).

Продукт, герценовский «лишний человек», появление которого, однако, неотъемлемо от «раскрытия внутреннего человека» («герой интересует автора как инструмент исследования жизни», как у Лермонтова) (Жук 1968: 6768), нарочито позиционируется в сюжетике, построенной на «вечной коллизии» (МАнн 1969: 265), и в интерпретации Белинского несет на себе примету сакрального: «Это - человек, понятие общее, родовое, во всей общирности этого слова, во всей святости его значения». Сходным образом, латентный замысел о духовном росте человека скрывается за жестом критика сопоставить колосса-Бельтова и карлика-Круциферского (БЕлинский 10: 320, 322), где богиней правосудия суждено быть Круциферской. В отношении сложного историко-литературного контекста, в котором предстает Бельтов, уместно учесть теорию, в соответствии с которой феномен «лишнего человека» тесно связан с эпохой «безгеройности» (Л. М. Лотман) 30-40 гг., «когда героя в русской литературе объективно нет и быть не может». Вместе с тем, менее вероятно, что его возникновение вполне независимо от «исторически предыдущих героев» (НиколАЕВ-ШвецОвА 2014: 131, 137). У Белинского высказана мысль о динамике метаморфозы Бельтова, трансмутации его в тип, напоминающий лермонтовского героя. Помимо этих этапов и автобиографических предпосылок, на конструирование герценовского «лишнего человека» проливают свет неустанные попытки Герцена выйти из терминологического заблуждения по поводу истолкования понятия «эгоизм», зафиксированные в статье 1847 года. Ход мысли Герцена кульминирует как раз в утверждении устремленности индивида к самопознанию: «Что такое эгоизм? Сознание моей личности, ее замкнутости, ее прав? [...] Где оканчивается эгоизм и где начинается любовь? [...] Не есть ли эгоизм то же с индивидуализацией, с этим сосредоточиванием и обособлением, к которому стремится все сущее как к последней цели?» (II, 96). Над холодным эгоизмом, сосредоточенностью в себе и на себе, атрибутируемым «лишнему человеку», несомненно берет верх самонаблюдение, самоанализ, - характерные для нарцисса. 
Господствующая в романе атмосфера, создаваемая латентной дилеммой вокруг сущности эгоизма, озвучена в замечании интерпретатора: изолированность Бельтова, отсутствие «союзников» объясняется тем, что в итоге его окружают «все такие же одинокие лишние люди» (ИвАнов-РАзумник 1911: $236){ }^{7}$ Бельтов сигнализирует поворотный пункт в созревании типа. Э. Чансиз считает, что если в изображении литературных антецедентов акцент падает на поведение и следствия поступков, то Герцен взялся за корни этого типа, стараясь разъяснить происхождение его (СHANCES 1978: 53). Новаторство Герцена мы склонны видеть в стремлении раскрыть психологические аспекты персонажа, усложненном поисками вечного, издревле существующего прототипа. Показателен в этом отношении латентный мотив стремления к свету, констатированный в связи с характером бездельника Бельтова в зеркале конфликта между мещанством и индивидуализмом: «Жил он только для того, чтобы „промаячить жизнь“...» (ИвАнов-РАзумник 1911: 236).

Мотив самораскрытия, составляющий сущность характера Бельтова далее интонируется автобиографизмом, ${ }^{8}$ портретом, написанным Жозефом со своего юного ученика: ведь последний сразу вызывает ассоциации с портретом Герцена, работы Витберга, попавшим в текст в качестве своего рода «зеркального отражения» реального артефакта, портрета автора. Согласно нашей рабочей гипотезе, ввиду нагроможденности мотивов самосозерцания, рефлексии (последняя для Бельтова оказывается губительной) не будет преувеличением предположить, что душевный склад Бельтова граничит с нарциссизмом. С другой стороны, раннее кредо Герцена о модусе порождения текста здесь перерастает в некий инвариант, сплав автопортретирования и самосозерцания: «Я решительно хочу в каждом сочинении моем видеть отдельную часть жизни души моей, пусть их совокупность будет иероглифическая биография моя» (XXI, 76). Целесообразно посему показать на конкретных примерах скрытый интертекстуальный диалог с мифологемой о Нарциссе и «симптомы» нарциссизма в тексте романа на уровнях словесного оформления и характеристики Бельтова. ${ }^{9}$

Начнем с «оранжерейного», т. е. цветочного воспитания протагониста. Самолюбие как кардинальная примета нарциссической личности присуще уже его отцу. Прочитав письмо Софи из Петербурга, обвиняющей его в «мелком самолюбии», Бельтов старший как бы погружается в самонаблюдение, оказываясь в роли окаменевшего при зове Эхо Нарцисса, в позитуре лицом к зеркальной глади: «обернулся головою к окну. Два часа просидел он в этом положении...» (IV, 84-85). Если сюжет античной мифологемы центрирован

${ }^{7}$ Г. Н. Гай в своей монографии идентифицирует кроме Бельтова всего-навсего один персонаж («вольнодумца», дядюшку отца Бельтова) как воплощение «лишнего человека» (ГАй 1959: 83).

${ }^{8}$ Скрытыми автобиографизмами текст романа изобилует (см. ЙожА 2018).

9 Потенциальная соотносимость фигуры «лишнего человека» и психики нарцисса косвенно затрагивается в монографии А. Позова, назвавшего Печорина нарциссом (Позов 1975: 102, 110-111). 
на мотивах зеркального отражения и звука / голоса (Эхо), то недаром у Бельтова старшего в конце сцены возникает ощущение «шума в ушах». Символика числа два, соотносимая в этом фрагменте с конкретной ситуацией оторванности от Софи, пронизывает ткань романа начиная с структуры, определяемой разделением романа на две части, вплоть до принципиального для него дуализма, сказывающегося, к примеру, в оппозиционных парах «Запад и Россия», «тело и душа», «индивид и коллектив». Они детерминируют путь амбивалентного Бельтова. Пристрастие автора к окнам уловимо и в описании изменений в обстановке «мастерской» протагониста: вопреки выбору карьеры скульптора, деятеля искусства, требующего света, «нижние стекла у окон его кабинета завесились непроницаемыми тканями» (отрицание «зеркального» принципа мимесиса и разночтение о сущности таланта, воспринимающее талант как синоним доведенного до крайности индивидуализма). Таким образом истинное художество как бы происходит из сферы мрака. Как эквиваленты, зеркальные отражения друг друга в этом интерьере размещены «два черепа», «возле» них «небольшая Венера» (IV, 105), как бы дополняя оппозиционную пару «Эрос-Танатос» и симультанно совмещая в себе из-за присутствия мотива окна и потенциальную ассоциацию с фигурой богини любви, получившей ключевую роль в судьбе древнегреческого юноши, который восстал против нее.

Изучивший «сердце человеческое» «по Плутарху» Жозеф (сходство с Герценом, соткавшим свой роман из биографий главных персонажей, очевидно), неисправимый «холодный мечтатель», заменив Бельтову отца, учит воспитанника по Плутарху. Иначе говоря, автор картины воспитанника сотворит Бельтова, если угодно, по образу своему, тем впадая в ересь человекобожия. ${ }^{10}$ Ту же модель сотворения Тургеневым Рудина Герцен иронически комментирует на страницах «Былого и дум»: «Тургенев, увлекаясь библейской привычкой бога, создал Рудина по своему образу и подобию; Рудин Тургенев 2-й, наслушавшийся философского жаргона молодого Бакунина» (XI, 359). Гувернер как бы предстоит как носитель душевного склада отца, промежуточный и контрастированный характер, наделенный чертами нарцисса, который предвещает судьбу Бельтова: «Негодующий на Европу», противостоящий пошлой среде и интеллектуально превосходящий окружающих его в гармонии с парадигмой «лишнего человека» Жозеф, повинуясь

${ }^{10}$ Данная мысль не противоречит теории об инспирированности романа христианскими ценностями и этикой, где выделенные исследователем мотивы «девственный взгляд» и любовь к ближнему, составляющие идеал, проповедуемый Жозефом, наряду с темой «страдания», т. е. «содержания земного существования» как последствия заблуждения Круциферской и Бельтова (САРСЕНОВА 2012: 147-149) перекликаются с представлением о Бельтове-искусителе, изложенным в истолковании В. Кантора, идентифицировавшего присутствие схемы ветхозаветного искушения сатаной в истории любовного треугольника (КАНТОР 2012). Примиримость полюсов одержимости нарцисса «грандиозной идеей» и духовности верифицирована результатами статистических исследований, свидетельствующих о склонности нарциссического индивида либо к погружению в нетрадиционные разновидности и практики духовности, либо к религиозности (WINK-DILLON-FAY 2005: 144-146, 156). 
тайному зову внутреннего голоса, решается на переезд в Россию, на эскападу, как раз во время прогулки на берегу озера: «Печальный, бродил он по берегам своего озера..., вдруг воображение указало ему на север» (IV, 90). Сюжетный элемент состояния хандры, сочетаемый с образом озера и предвосхищающий поворот в судьбе человека, подчиняясь закону зеркальных эффектов, последовательно применяемых автором, повторяется в истории Бельтова. Согласно математически точному построению текста, по приезде в городок протагониста ожидает такая же картина, представляющая собой своего рода лакановский «момент порога»: проходя дом Круциферских, воплощающий собой счастье семейного очага, Бельтов бессознательно встречает атмосферу, уподобляемую всезнающим автором «летнему вечеру», «когда пруд стелется как металлическое зеркало, золотое от солнца» (IV, 126). Неосознание им рокового значения встречи символически разоблачает недальновидность и отказ персонажа от гармонии, предваряя причиняемое им разрушение. Выделяющиеся в кусочке текста слова зеркало, пруд, помимо намека на древнюю гадательную функцию водной глади, также включают в себе семантику „познания“, столь важную в истории о Нарциссе, долголетие которому было предречено прорицателем, «коль сам он себя не увидит» (Овидий 1994: 64), т. е. не познает. Плутарх, автор «Параллельных жизнеописаний», усвоенных благодаря рационалистическому воспитанию, латентно инициирует диалог с автором «Метаморфоз», повествующим биографии мифологических персонажей. Правда, нарциссические искра гениальности, одержимость грандиозной самостью (Кохут 2003: 17-75), контрастируемые Белинским с неимением «достойного поприща» (БЕлинский 10: 321-322), побуждает Бельтова дать волю своим нарциссическим энергиям на поприще науки или же - художества, но периоды регрессии препятствуют самореализации героя. Окончательный провал, попытка найти убежище в сфере идиллической и идеализируемой гармонии, обретаемой через любовное счастье, оборачиваясь фиаско, симультанно вскрывают сущность характера Бельтова, неспособность к привязанности к другому. Последний удар равнозначен полной лишаемости его прав на контакт с любым индивидом.

Вышеупомянутый лакановский момент мелькает как предвестие о кульминационном пункте действия, о потенциальном поворотном пункте в судьбе Бельтова, любовной встрече на скамейке с Круциферской. Встреча мерещится как шанс на постижение чаемой гармонии, они достигают грани, за которой открывается путь к преодолению собственной гордости и эгоизма. Но грандиозно замышленная сцена превращается в монологи двух. Увертюрой к ней служат функциональные штрихи публичного сада, где визуальный образ «беседки», провоцирующий мысль о предстоящем разговоре, прикреплен к семантике ,дух античности“ и „непонимание“ через ассоциативную цепь , китайской грамоты“: беседка построена «в китайско-греческом вкусе». При этом «стих Озерова» через имя автора предрекает появление водяной глади, симультанно оперируя штампом романтического двоемирия: «Есть боги, - а земля злодеям предана» (IV, 169-170). Стих, функционирующий 
как эпиграф к сцене, предвосхищает, зеркально проецирует последующие за ним события, сгущая в себе развязку эпизода и всего романа. Прием базирован на размноженном эффекте «зеркало в зеркале», вызывающем в памяти вышеупомянутую формулу Герцена о собственной поэтике. Подчеркнем, что мотив зеркальности в обоих случаях попадает в ауру культур, - китайской и древнеегипетской, имеющих трудно расшифровываемый алфавит, если угодно, - изолированные вербальные сферы: в аранжировке свидания Бельтова и Круциферской, меняющихся ролями Нарцисса и Эхо, локус уже приурочен к Овидиеву сюжету: дама и кавалер, будучи по одежде негативными зеркальными отражениями друг друга (она «в белом бурнусе», он - «в черном пальто»), приходят к берегу реки, «в разливе» своем напоминающей благодаря все растущей глади воды (симультанно соответствующей кульминации эмоций) скорее озеро.

Разговору двух предшествует описание, изобилующее подобно тексту Овидия мотивами звука/шума/голоса: пейзаж переполнен шумом от пассажиров всех сословий, экипажей, «топотом» и «мычанием» животных, «громким разговором крестьян». Прерывающие «свои речи» дама и кавалер «слушали даль», немота мужчины, чуть ли не буквально приравниваясь к отзвуку печали Любоньки, передается своего рода оксюморонной, синестетической фразой: «его душа звучит потому, что ей грустно» (IV, 170-171). Ключевой для истории Овидия мотив отзвука сказывается и в языковом оформлении фраз способом повторов, эхо-повторов в диалогах: «Как хорошо здесь... [...] Как везде»; «отчего человек умеет всем наслаждаться, во всем находить прекрасное, кроме в людях? - Понять можно, отчего, но от этого не легче будет» (даже двойной повтор не содержит ответа, усиливая момент никак несбывающегося разговора, на котором центрирована история Нарцисса и Эхо). Несогласие, непонимание, отказ от любви тенденциозно маркируют мотив неосуществимого диалога. «Я сомневаюсь в продолжительной полноте такого сочувствия; это все говорится только. Люди, совершенно сочувствующие, еще не договорились до тех предметов, где они противоположны...». В реплике Любоньки как в отзвуке модифицируется значение глагола, носящее семантику приставки до- в смысле 'достижение цели', симультанно намекая на шанс единения двух, совместимого с актом нарциссического самолюбования: «Все же, пока они договорились, могут быть минуты полной симпатии, где они не мешают друг другу наслаждаться и природой и собой» (IV, 172). В подобном духе, устами Бельтова, схатывающего роль нимфы Эхо, удваивается ее вопрос: «Какие? Не собственные ли это капризы? - заметила Круциферская. - Какие? - повторил Бельтов...» (IV, 172). Как призрак и тень его преследует мысль о внутреннем торможении, препятствующем исполнению счастья: человек «не смеет дать воли ни одному чувству» $(\mathrm{IV}, 173)$. Безостановочно льющийся поток речи, нескончаемый никудышный разговор противостоит реализации чувств. Бессилие «лишнего человека» перед любовью сам Бельтов концептуализирует посредством отождествления любви и говора: «Так отчего же, скажите, я не имел силы прийти 
к ней и взять ее за руку, и смотреть в глаза, и говорить... и говорить». Другими словами, Эрос и Логос вытесняют друг друга. Ввиду - по собственному выражению Бельтова - «желания исповеди» диалог в этом пункте скорее приобретает характер психоаналитической сессии, проводимой в поисках причин меланхолии Бельтова (атрибута «лишнего человека»). ${ }^{11}$ Фиаско предуготовлено собственно Бельтовым, четко осознающим с самого начала бесперспективность отношений с замужней дамой, отличающейся вдобавок сильной натурой и непоколебимой супружеской верностью. Приключение, посему влекущее за собой неотвратимую катастрофу, для нарцисса останется привычным для него кокетством, праздной попыткой влюбить в себя. Недаром ответ Круциферской - всего лишь эхо того, что он сам знает: «оттого, что эта женщина принадлежит другому и любит его» (IV, 173-174). Вынесен вердикт, понимаемый как диагноз: все это излишне, разговор лишен смысла: «Ах, Бельтов, Бельтов, зачем все это, зачем этот разговор?» (IV, 173).

Крушение страстей внушает провал и в плане самопознания, неудача высвобождает губительные энергии, «лишний человек» снова обретает закодированный в нем вредоносный характер ${ }^{12}$ благодаря негативной семантической ауре прилагательного, связанного по этимологии со словом лихой (MÁgocsi 2017: 46-47); скиталец в поисках собственного я совершает эскападу, оставляя за собой жертвы: Любонька наподобие высохшей от тоски Эхо увядает, реальное счастье семейства уничтожено, матери Бельтова предстоит роль сиделки. Страшная цепь событий, воспроизводящая ультимативную антиномию бытия «эгоизм-мрак, любовь-свет», сформулированную Герценом (XXI, 101), соотносима с «угрозой нарциссизму» [курсив - Э. Ф.] (наносившей удары Бельтову в виде серии неудач), которую Э. Фромм оценивает как «один из важнейших истоков агрессии» (ФРомм 1994: 175). Герцен явно выступает как толкователь мифа: кроме проанализированного текста, в пользу этого утверждения говорит максимально сознательное апеллирование к имени древнегреческого юноши в сопровождении мотива картинного изображения лица в повести «Доктор, умирающий и мертвые»: доктор, вспоминая «портрет временного правительства 48 года», говорит: «Впереди сухая фигура Ламартина... Зачем он тут... какого „падшего ангела“ пришел отпевать или подымать старый Нарцисс?» $(\mathrm{XX}, 526)$.

\section{Литература}

БЕЛИНСКИЙ = БЕлИнскиЙ В. Г. Полное собрание сочинений в 12 томах. Москва: «Издательство Академии наук СССР», 1953-1956.

БРОдский 1945 = БРодский Н. Л. М. Ю. Лермонтов. Биография. Москва: «ОГИЗ», 1945.

${ }^{11}$ Об исповедальности прозы Герцена см. Исупов 1995: 44.

${ }^{12}$ Параллелизм между Бельтовым и Печориным, которые оба появляются на фоне мирной жизни и приносят с собой разрушение (a gust of destruction) (СHANCES 1978: 50). 
Бурсов 1960 = Бурсов Б. Лишние слова о «лишних людях». Bonpocbl литературы 1960/4: 105-118.

ГАЙ 1959 = ГАЙ Г. Н. Роман и повесть Гериена 30-40-х годов. Киев: «Издательство Киевского университета», 1959.

ГЕРцЕН 1954-1966 = ГЕРцЕН А. И. Собрание сочинений в 30 томах. Москва: «Наука», 1954-1966.

ГинзБУрг 1997 = ГинзБурГ Л. Я. Автобиографическое в творчестве Герцена. В кн.: ЛАНСКИЙ Л. Р., МАКАШИН С. А. (ред.) Гериен в кругу родных и друзей. Кн. 1. (Литературное наследство 99.) Москва: «Наука», 1997. 7-54.

Горький 1953 = Горький М. История русской литературы. В кн.: ПутинцеВ В. А. (сост.) А. И. Гериен в русской критике. Москва: «Гослитиздат», 1953. 248-257.

ГрОТХУСЕН 2014 = ГРОТХУСЕН 3. «Лишний человек» как герой своего поколения в русской литературе XIX в. Литературоведческий журнал 34 (2014): 96-99.

Гурвич-ЛишинеР 1996 = Гурвич-ЛишинеР С. Герцен на пороге XXI века. Bonpocbl литературы 1996/5: 133-136.

ДостоЕВСКий 1979 = ДостоЕВский Ф. М. Полное собрание сочинений в 30 томах. Т. 19. Ленинград: «Наука», 1979.

ДрыЖАКОВА 2004 = ДРыЖАКОВА Е. Н. Шесть европейских «масок» Онегина в восприятии Герцена. В кн.: Пушкин. Исследования и материальл. Т. 16-17. Санкт-Петербург: «Наука»: 243-250.

Жук 1968 = Жук А. «Герой нашего времени» и проза Герцена 1830-1840-х годов. Филологические науки 1968/6: 62-74.

ИВАНОВ-РАЗУМНИК 1911 = ИвАНОВ-РАЗУМНИК Р. В. История русской общественной мысли в 2 томах. Т. 1. Санкт-Петербург: «Типография М. М. Стасюлевича», 1911.

Исупов $1995=$ Исупов К. Г. «Историческая эстетика» Герцена. Русская литература 1995/2: 32-46.

ЙожА 2018 = ЙожА Д. З. Зеркало в зеркало. Герцен: автобиографичность и самопознание. В кн.: КРОо К. (ред.) Голоса русской филологии из Будапешта. Литературоведение и языкознание на Кафедре русского языка и литературы Университета им. Лоранда Этвеша. Budapest: Eötvös, 2018. 82-93.

КАНТОР 2012 = КАНТОР В. Кто виноват, или безумие исторического процесса. Вопросы литературы 2012/6: 295-331.

Кохут 2003 = Кохут Х. Анализ самости. Систематический подход к лечению нарииссических нарушений личности. Москва: «Когито-Центр», 2003.

МАнН 1969 = МАнН Ю. В. Философия и поэтика «натуральной школы». В кн.: Проблемы типологии русского романтизма. Москва: «Наука», 241-305.

НиКОЛАЕВ-ШВеЦОВА 2014 = НиКОЛАЕВ Н. И., ШВЕЦОВА Т. В. Русская литература 30 40-х гг. XIX в. «Ожидание героя». Вестник Томского государственного университета. Серия «Филология» 2014/3: 125-142.

Овидий 1994 = Овидий: Собрание сочинений в 2 томах. Т. 1. Санкт-Петербург: «Биографический институт „Студиа Биографика“», 1994.

Позов 1975 = Позов А. Метафизика Лермонтова. Мадрид, 1975.

САРСЕНОВА 2012 = САРСЕНОВА И. Ж. Герценовская концеПция Личности в контексте христианской традиции. Гуманитарные исследования 2012/1: 144-150.

Семенов 1989 = Семенов В. Гериен. Москва: «Современник», 1989.

Фромм 1994 = Фромм Э. Анатомия человеческой деструктивности. Москва: «Республика», 1994.

ЭЛЬСБЕРГ 1948 = ЭЛЬСБЕРГ Я. А. И. Гериеен. Москва: «ОГИЗ», 1948. 
Armstrong $1985=$ Armstrong J. M. The True Origins of the Superfluous Man. Russian Literature 17 (1985): 279-296.

Chances $1978=$ Chances E. B. Conformity's Children. An Approach to the Superfluous Man in Russian Literature. Ohio: Slavica Publishers, 1978.

Clardy-Clardy 1980 = Clardy J. V., Clardy B. S. The Superfluous Man is Russian Letters. Washington: University Press of America, 1980.

Mágocsi 2017 = MÁGOCsi Nyina: Специиальная банковская лексика. Основные исторические этапь формирования и некоторые особенности современного состояния. Диссертация на соискание степени PhD. Budapest, 2017.

WinK-Dillon-Fay 2005 = Wink P., Dillon M., FAY K. Spiritual Seeking. Narcissism and Psychotherapy. How Are They Related? Journal for the Scientific Study of Religion 44 (2005): 143-158. 